\title{
Predictors of Foreign Language Anxiety: A Study of College-Level L2 Learners of Chinese
}

\author{
Han Luo \\ Lafayette College, U.S.A.
}

\begin{abstract}
This study investigated seven learner variables (i.e., age, motivation, perception of the difficulty of the Chinese language, self-perceived achievement, self-perceived language learning ability, self-expectation in the Chinese class, and perception of the importance of the Chinese language) as potential predictors of Chinese language learning anxiety. Correlation analyses showed that all seven variables were significantly correlated with anxiety level in isolation. Perception of the difficulty of the Chinese language and age were found to have positive relationships with anxiety, whereas the remaining five variables were reported to have negative relationships. Multiple regression analysis revealed that all the variables except self-expectation in the Chinese class and perception of the importance of the Chinese language contributed significantly to the prediction of Chinese language learning anxiety when examined simultaneously. The five significant predictors altogether explained $34.7 \%$ of the variance in anxiety. Perception of the difficulty of the Chinese language was found to be the best predictor and self-perceived achievement the second-best predictor, followed by self-perceived foreign language learning ability, age, and motivation.
\end{abstract}

Keywords: Foreign Language Anxiety; Chinese language learning anxiety; Chinese; L2 learners of Chinese; Predictor

\section{Introduction}

Thanks to Horwitz, Horwitz and Cope's (1986) seminal work on Foreign Language Anxiety, the study of anxiety has attracted the attention of an increasing number of researchers and language teachers in the past three decades. In their view, Foreign 
Language Anxiety is a situation-specific anxiety independent of other types of anxieties. They defined Foreign Language Anxiety as "a distinct complex set of self-perceptions, beliefs, feelings and behaviors related to classroom language learning arising from the uniqueness of the language learning process" (p. 128). They also identified three anxieties related to Foreign Language Anxiety: communication apprehension, fear of negative evaluation, and test anxiety, to help language teachers and scholars understand the nature of Foreign Language Anxiety. In addition, they offered an instrument, the Foreign Language Classroom Anxiety Scale (FLCAS), to measure Foreign Language Anxiety.

After the introduction of the FLCAS and a number of other similar measures (e.g., Gardner, 1985; MacIntyre \& Gardner, 1994), researchers were able to measure Foreign Language Anxiety relatively more precisely. Many studies have shown that Foreign Language Anxiety is a common emotional reaction to foreign language learning experienced by foreign language learners whether it be in high schools, small colleges or large major universities, whether the target language be Spanish, French, Japanese or any other languages, whether language learners be freshmen or graduate students (e.g., Aida, 1994; Ganschow \& Sparks, 1996; Horwitz, 1986; MacIntyre \& Gardner, 1989), and whatever the proficiency level of language learners (e.g., Coulombe, 2000; Liu, 2006). Studies in a variety of language learning contexts have found that approximately one-third of students studying a foreign language experience at least a moderate level of Foreign Language Anxiety (Horwitz, 2001).

Foreign Language Anxiety has also been found to have various negative effects on second/foreign language learning (Horwitz, Tallon, \& Luo, 2010; Luo, 2013b; MacIntyre, 1999;), including academic effects (Gardner \& MacIntyre, 1993a; MacIntyre \& Gardner, 1991a;), cognitive effects (Eysenck, 1979; Sarason, 1980; Tobias, 1979, 1986), social effects (MacIntyre \& Charos, 1996; MacIntyre \& Gardner 1991a, 1991b), affective effects (Phillips, 1992; Spitalli, 2000), and personal effects (Cohen \& Norst, 1989; Horwitz \& Young, 1991; Price, 1991).

The majority of studies on Foreign Language Anxiety have focused on foreign language learners of commonly taught languages such as Spanish, French, and German. In the past decade, as China is playing an increasingly important role in world economy and politics, there has emerged an international interest in learning the Chinese language. Thus, studies on the anxiety experiences of Chinese language learners have started to catch up. Several doctoral dissertations (Le, 2004; Luo, 2011; Zhao, 2009) and an increasing number of empirical studies (e.g., Luo, 2013a, 2014a, 2014b, 2015; Shi, 2007; Xiao \& Wong, 2014; Zhang, 2001, 2002; Zhang \& Wang, 2002; Zhao, Guo, \& Dynia, 2013; Zhao \& Whitchurch, 2011) have focused on Chinese language learning anxiety.

These studies have addressed a number of issues of Foreign Language Anxiety among Chinese language learners, including but not limited to the anxiety of Chinese heritage learners (Luo, 2015; Xiao \& Wong, 2014), development of a language learning anxiety scale specific to the Chinese language (Luo, 2014a), skill-based Chinese language learning anxiety (Luo, 2014b; Zhang, 2002; Zhao, Guo, \& Dynia, 2013), and factors associated with Chinese language learning anxiety (Luo, 2013a; Zhao \& Whitchurch, 2011). A large number of factors, both categorical background variables and quantitative 
learner variables, have been identified as related to Chinese language learners' anxiety in these studies. The influence of a wide range of background variables on Chinese language learning anxiety has been investigated in depth (e.g., Luo, 2013a; Zhao \& Whitchurch, 2011; Zhao, Guo, \& Dynia, 2013). However, the relationship between quantitative learner variables and anxiety among Chinese language learners, especially college-level L2 learners of Chinese has received much less attention.

In order to bridge the research gap, this study attempts to focus on college-level learners of Chinese as L2 and examine the relationship between Chinese language learning anxiety and seven quantitative learner variables that have been identified as associated with Foreign Language Anxiety in the literature. These variables are motivation, age, self-perceived achievement, perceived difficulty of the Chinese language, self-perceived language learning ability, self-expectation in the Chinese language class, and perceived importance of learning Chinese.

\section{Literature Review}

Many researchers have realized the significance of investigating the relationship between Foreign Language Anxiety and other learner variables. For example, Aida (1994) held that "studies examining the relationship between anxiety and learner characteristics will help us increase our understanding of language learning from the learner's perspective and provide a wider range of insights" (p. 165). Similarly, Tóth (2007) pointed out that exploring the relationship between anxiety and other learner variables "can reveal what kind of language learners are more susceptible to experiencing anxiety about L2 learning and communication, thereby increasing current understanding of the factors precipitating FLA (foreign language anxiety)" (p. 123).

Scholars and researchers have identified a number of quantitative learner variables as related to Foreign Language Anxiety. The seven selected variables in this study are among the most widely discussed. Below is a brief review of previous research on the seven variables in relation to Foreign Language Anxiety.

\subsection{Motivation}

Scholars and researchers believe that anxiety and motivation are two theoretical constructs closely related to each other. For example, anxiety has formed a component of the Attitudes/Motivation Test Battery (Gardner, 1985) in the framework of the socioeducational model. Clément $(1980,1986)$ viewed anxiety and motivation as two closely related learner characteristics in his social-context model. Phillips (1992) concluded that anxiety could have a negative impact on students' attitudes and motivation toward language study. Liu and Huang (2011) found a significant negative correlation between anxiety and language learning motivation among EFL learners. However, Tóth (2007) examined the relationship between motivation and Foreign Language Anxiety quantitatively and found that the correlation between motivation and Foreign Language 
Anxiety did not reach a significant level. As can be seen, the relationship between motivation and anxiety needs further clarification.

\subsection{Age}

Many language learners intuitively believe that younger learners are better at learning foreign languages than their adult counterparts (Horwitz, 1988). This intuition seems to be justified to some extent as some research has shown that younger people tend to be able to speak a foreign language with less accent and have stronger ability in mastering the finer points of language such as phonology and morphology (Lieberman, 1984; Newport, 1986). Studies on age and test anxiety have generally reported a positive relationship between age and test anxiety (Crook, 1979; Hunt, 1989), indicating older language learners are more anxious over taking tests. In a study exploring 26 associated variables of anxiety, Onwuegbuzie, Bailey, and Daley (1999) found that age was a significant predictor of Foreign Language Anxiety and that older students had higher levels of anxiety. It would be interesting to see whether age affects the anxiety levels of L2 learners of Chinese.

\subsection{Self-perceived Achievement}

Many studies have investigated the relationship between Foreign Language Anxiety and second/foreign language achievement. These studies have generally reported a consistent moderate negative relationship between language anxiety and language achievement (Horwitz, 2001). Researchers have most commonly used final course grades and standardized proficiency tests to measure language achievement in language anxiety studies (Aida, 1994; Horwitz, 1986; MacIntyre \& Gardner, 1994; Phillips, 1992). However, many studies have shown that learners' self-perceived achievement is a better predictor of Foreign Language Anxiety than actual achievement based on course grades or objective proficiency measures (Cheng, 2002; Gardner \& MacIntyre, 1993b; Tóth, 2007). For example, MacIntyre, Noels, and Clément (1997) asked students to rate their language proficiency levels themselves and discovered a negative relationship between anxiety and students' self-ratings. Onwuegbuzie, Bailey, and Daley (1999) found expected overall average for the language courses to be the best predictor of Foreign Language Anxiety among 26 potential predictors. An investigation of the relationship between anxiety and self-perceived achievement among college-level L2 learners of Chinese in the United States may add to the existing body of knowledge on this issue.

\subsection{Perception of the Difficulty of the Target Language}

Some studies seem to indicate that the target language has an effect on Foreign Language Anxiety (Luo, 2012). For example, compared to the anxiety levels of learners of other languages in other studies, Chinese language learners in Chinese study-abroad programs in Le's (2004) study experienced substantially higher levels of anxiety, perhaps due to the difficulty level of Chinese. Saito, Garza, and Horwitz (1999) found that levels of 
foreign language reading anxiety were significantly different for the three target languages (Japanese, Russian and French) examined in their study. When reading, learners of Japanese were the most anxious, followed by the French participants, with the Russian participants experiencing the lowest levels of reading anxiety. The researchers argued that "reading Japanese provoked higher anxiety levels than reading Russian or French was anticipated due to the unfamiliar and non-Roman writing system as well as the foreign cultural content" (p. 212). In Aida's (1994) study, the anxiety level of students of Japanese was slightly higher than that of Horwitz's (1986) study of Spanish language learners. According to Aida, this result was understandable because "students may feel more anxious in learning a non-western, foreign language like Japanese than in learning commonly taught Western languages such as Spanish" (p. 158). However, the contribution of perception of the difficulty of the target language to Foreign Language Anxiety has hardly been investigated. Chinese is a relatively difficult foreign language for L2 learners due to its tonal and non-alphabetic nature. An exploration of the contribution of perception of the difficulty of the Chinese language to anxiety may provide new insight to this issue.

\subsection{Self-perceived Language Learning Ability}

Foreign language aptitude or learning ability as a potential factor contributing to Foreign Language Anxiety was proposed by Sparks and Ganschow (Ganschow \& Sparks; 1996; Sparks \& Ganschow, 1995). Ganschow and Sparks (1996) reported a medium size negative correlation $(r=-.43, p=.008)$ between learners' Foreign Language Anxiety and language aptitude as measured by the Modern Language Aptitude Test. However, Tóth (2007) found foreign language aptitude not to be significantly correlated with anxiety among firstyear Hungarian English majors. Compared to foreign language learning ability based on objective measures, self-perceptions of language learning seem to be a more established predictor of Foreign Language Anxiety. Ganschow and Sparks (1991) found that students' perception of the ease of learning a foreign language to be a strong identifier of foreign language anxiety. According to Ganschow et al. (1994), students with high levels of anxiety perceived their language course to be difficult, whereas students with low levels of anxiety perceived their language course to be easy. Horwitz $(1990,1995)$ reported that highly anxious learners were more likely to consider language learning a difficult task than their low-anxiety counterparts. However, very few studies have directly examined the relationship between self-perceived language learning ability and Foreign Language Anxiety. Thus, a quantitative study examining self-perceived foreign language learning ability in relation to anxiety among L2 learners of Chinese seems to be interesting.

\subsection{Perceived Importance of the Target Language and Self-expectation}

The last two selected learner variables, namely, perception of the importance of the target language and self-expectation in the foreign language class, have not received much attention in anxiety research to date. These two variables were identified from Luo's (2011) 
interview study with Chinese language learners and teachers, who reported perception of the importance of the Chinese language and self-expectation in learning Chinese to be contributing factors of anxiety in Chinese classes. More specifically, according to the Chinese language learners and teachers being interviewed, students who viewed Chinese as of greater importance to them and who had higher self-expectation in learning Chinese, had a greater propensity to experience high levels of anxiety in learning Chinese. However, this view has not been investigated quantitatively. It is believed that a quantitative study of the relationship between the two variables and anxiety may be necessary.

\section{Research Questions}

As the above literature review shows, the seven selected variables have been identified as predictors of Foreign Language Anxiety. However, studies on some variables produced mixed results (as in the case of motivation), some of the correlates have not received sufficient attention (as in the case of age and perception of the difficulty of the target language), and others were identified from preliminary qualitative studies (as in the case of perception of the importance of the target language and self-expectation in language learning). Moreover, most studies have relied on correlation analysis and examined the relationship of a given variable to Foreign Language Anxiety in isolation (e.g., as in the case of self-perceived achievement and self-perceived language learning ability). To date, no research has been done to investigate the simultaneous effect of all the seven variables on Foreign Language Anxiety in one study. Thus, the unique contribution of a given variable to Foreign Language Anxiety when other learner variables are present remains to be further researched. In addition, the relationship between anxiety and quantitative learner variables among college-level L2 learners of Chinese is still under-explored.

To bridge the research gap, the present study attempts to examine all the seven learner variables (i.e., motivation, age, self-perceived achievement, self-perceived language learning ability, perception of the difficulty of the Chinese language, perception of the importance of the Chinese language, and self-expectation in learning Chinese) as potential predictors of Chinese language learning anxiety in the same sample of learners, i.e., college-level L2 learners of Chinese in the United States. More specifically, this study seeks to answer the following two research questions:

1. What is the relationship between Chinese language learning anxiety and each of the selected seven learner variables?

2. What relative contribution does each of the seven variables make to the prediction of Chinese language learning anxiety? 


\section{Methods}

\subsection{Participants}

Altogether, 428 (225 males, 202 females; 1 missing the gender indication) Chinese language learners at two large public universities in the U.S participated in this study and turned in valid responses. Among all the participants, 171 learners were identified as heritage learners with home exposure of Chinese, whose responses were then excluded from data analysis in this study. Therefore, participants of this study were the remaining 257 (147 males, 110 females) L2 learners of Chinese with an age range of 15 to 59 ( $M=$ 21.3, $S D=4.7$ ) from the two universities, with 112 participants from one university and 145 from the other. They were all taking credit-bearing Chinese language courses at the two universities: 128 took Chinese as an elective and 129 took it to fulfill requirements.

Among the 257 participants, 141 were taking first-year Chinese, 76 were in secondyear Chinese classes, and 40 were third-year Chinese language students. In terms of ethnicity, 186 of the participants were white, 4 were Chinese Americans with no home exposure of Chinese, 26 were Asian but not Chinese Americans, 19 were Asian international students, 16 were Hispanic, 1 was African American, and 5 were from other ethnic backgrounds.

\subsection{Instruments}

The instruments for this study included the Chinese Language Learning Anxiety Scale (Luo, 2014a) and a Background Questionnaire. The Chinese Language Learning Anxiety Scale is a 16-item self-report measure that consists of items scored on a 5-point Likert Scale, ranging from strongly agree to strongly disagree. In this scale, items were evenly distributed for anxieties related to the four skills, that is, speaking, listening, reading, and writing. This anxiety scale was reported to have high reliability and validity, with the internal consistency reliability (using Cronbach's Alpha) achieving .90 (Luo, 2014a). Chinese language learning anxiety was calculated as the sum of the number of items in the scales. The possible range of scores for Chinese language learning anxiety was 16-80.

In addition to background information such as gender, age, ethnicity, college year, proficiency level, native language, and heritage-learning status, the Background Questionnaire asked the participants to estimate a grade (i.e., A, A-, B+, B-, ..., F) they expected to get in the Chinese class, and provide a rating of motivation in learning to speak, comprehend, read, and write Chinese, self-perceived foreign language learning ability, the level of self-expectation in learning Chinese, perception of the importance of the Chinese language, and perception of the difficulty level of the Chinese language on a 5-point Likert Scale.

The possible range for "self-perceived achievement" (i.e., expected grades) was 1-7, with 1 corresponding to $\mathrm{F}$ and 7 corresponding to A. Participants' motivation in learning Chinese is calculated as the sum of ratings on motivation associated with the four skills. Thus, the possible range of scores for "motivation" was 4-20. The four variables, that is, 
perception of the difficulty of the Chinese language, self-perceived language learning ability, perception of the importance of the Chinese language, and self-expectation in learning Chinese, were each represented by one item on a 5-point Likert Scale. Therefore, the possible ranges for these four variables were all 1-5.

\subsection{Data Analysis Methods}

To investigate the relationship between anxiety and the seven selected learner variables, Pearson correlations and multiple regression analysis were used. Pearson correlations were computed to calculate the strength and direction of the relationship between anxiety and each of the seven variables. Multiple regression analysis was conducted to assess the effect of seven correlates simultaneously, to determine their relative contribution to the prediction of anxiety, and to identify the best predictors.

Before multiple regression analysis was computed, the researcher checked Cook's distance and Leverage values for outliers, examined the P-P plot for normality of residuals, plotted the standardized residuals against the standardized predicted values to check linearity and equality of variances (See Figure 1) and studied the correlation matrix of all the independent variables for multicollinearity. The maximum value of Cook's distance was $.004<4 /$ n, i.e., $4 / 257=.016$, and the maximum value of Leverage was $.027<(2 \mathrm{k}+2) /$ n, i.e., $\left(2^{\star} 7+2 / 257\right)=.062$, indicating no obvious outliers. A close examination of the correlation matrix showed that none of the correlations had a Pearson's coefficient of 0.80 or greater. Thus, all the results indicated that multiple regression analysis was appropriate for the current data.

\section{Results}

\subsection{Correlation Findings for Research Question 1}

The descriptive statistics of the seven variables are outlined in Table 1. Table 2 presents the correlations between each of the seven selected variables and Chinese as a Foreign Language (CFL) Anxiety. 

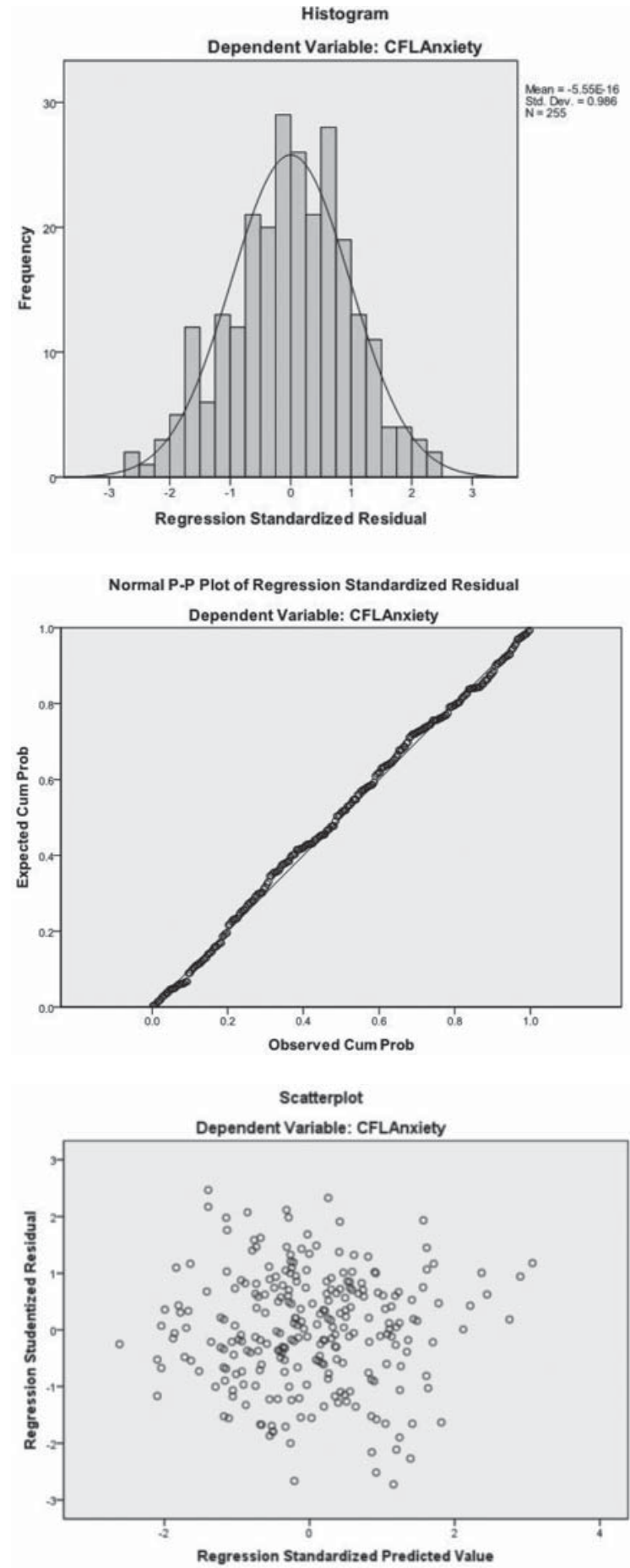

Figure 1. Residual plots 
Table 1. Descriptive statistics of the seven variables

\begin{tabular}{lcccc}
\hline & Minimum & Maximum & Mean & Std. Deviation \\
\hline Age & 15.00 & 59.00 & 21.27 & 4.71 \\
Perceived difficulty level of Chinese & 1.00 & 5.00 & 4.05 & 1.01 \\
Self-perceived achievement & 1.00 & 9.00 & 7.21 & 1.95 \\
Self-perceived language learning ability & 1.00 & 5.00 & 3.41 & 1.14 \\
Self-expectation in learning Chinese & 1.00 & 5.00 & 4.14 & .94 \\
Perception of Importance of Chinese & 2.00 & 5.00 & 4.38 & .80 \\
Motivation & 8.00 & 23.00 & 17.58 & 2.68 \\
\hline
\end{tabular}

Table 2. Correlations: the seven variables and CFL anxiety

\begin{tabular}{lcc}
\hline \multicolumn{1}{c}{ Predictor Variable } & Chinese Language Learning Anxiety & p \\
\hline Age & $.193^{* * *}$ & .000 \\
Perception of Difficulty & $.398^{* * *}$ & .000 \\
Motivation & $-.317^{* *}$ & .000 \\
Self-perceived Language Learning Ability & $-.356^{* *}$ & .000 \\
Perception of the Importance of Chinese & $-.214^{* *}$ & .000 \\
Self-expectation & $-.246^{* *}$ & .000 \\
Self-perceived Achievement & $-.390^{* *}$ & .000 \\
\hline
\end{tabular}

${ }^{* *}$ Correlation is significant at the 0.01 level

It can be seen from Table 2 that Chinese language learning anxiety correlated significantly with all the seven variables at the 0.01 level. Chinese language learners' anxiety was found to have positive correlations with two variables: perception of difficulty of Chinese $(r=.398)$ and age $(r=.193)$, and negative correlations with the remaining five variables, namely, self-perceived achievement $(r=-.390)$, motivation in learning Chinese $(r=-.317)$, self-perceived language learning ability $(r=-.356)$, self-expectation in learning Chinese $(r=-.246)$ and perception of the importance of Chinese $(r=-.214)$.

To put it another way, older students and students who perceived Chinese to be more difficult were more anxious; students who expected to get a higher grade, who were more motivated in learning Chinese, who perceived themselves to be better at learning languages, who had a higher expectation in learning Chinese, and who perceived Chinese to be of greater importance, tended to experience less anxiety in Chinese classes.

Perception of the difficulty of the Chinese language had by far the largest correlation $(r=.398)$ with Chinese language learning anxiety, which, by itself, explained $15.8 \%$ of the variance. The second largest correlate of anxiety was self-perceived achievement $(r=-.390)$, accounting for $15.2 \%$ of the variance. The strength of correlation between self-perceived language learning ability and anxiety $(r=-.356)$ ranked the third, followed by motivation, self-expectation in learning Chinese, and perception of the importance of Chinese, with age having the smallest correlation with anxiety. 
In order to provide a more detailed explanation for the relationship between age and Chinese language learning anxiety, the age range and the frequency of each age group of the sample were examined. The ages of the sample ranged from 15 to 59. The majority of the participants $(n=239)$ aged between 18 and 29 , with only 14 participants being 30 or above. Figure 2 shows the Scatter Plot of age and Chinese language learning anxiety. Based on the pattern shown in Figure 2, it takes caution to interpret the small negative correlation between age and anxiety. If only participants aged between 18 and 29 were studied, the correlation analysis between age and anxiety may have produced different results.

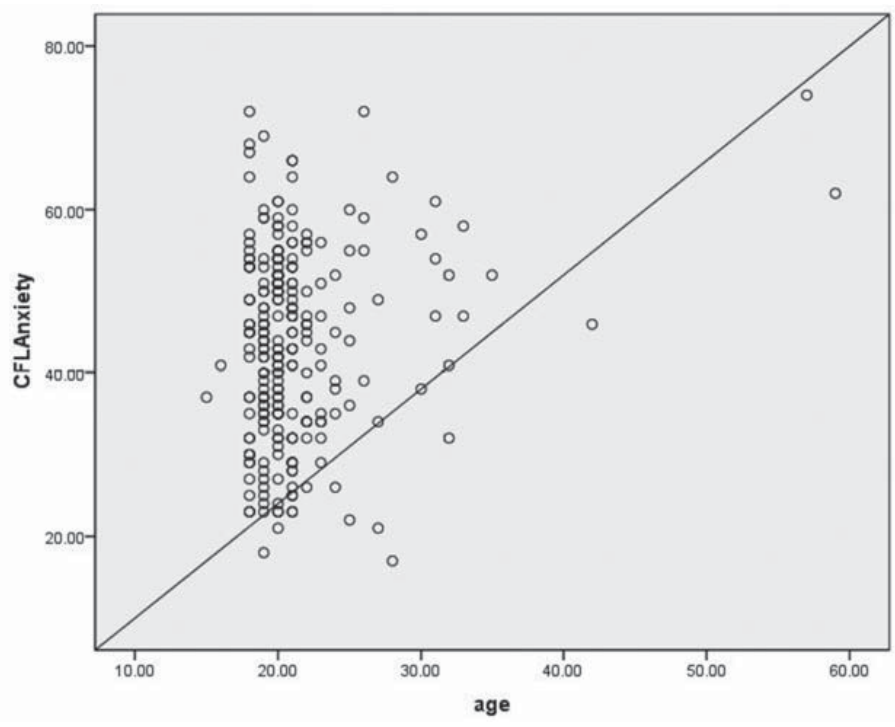

Figure 2. Scatter plot between age and CFL anxiety

\subsection{Multiple Regression Findings for Research Question 2}

This study used multiple regression analysis to examine the simultaneous effect of the seven selected variables on Chinese Language Learning Anxiety. More specifically, this procedure was used to determine the relative contribution of these variables to the anxiety level of L2 learners of Chinese and to identify the best predictors of Chinese Language Learning Anxiety. Table 3 presents the standardized regression coefficients, $t$ value, and squared partial correlation coefficients of the initial model, with all seven learner variables entered in the regression equation. The table shows the more parsimonious model suggested by the backward selection method.

The results in Table 3 shows that the seven variables together contributed significantly, $F(7,254)=19.06, p=.0001$, to the prediction of Chinese Language Learning Anxiety. The $\mathrm{R}$ value (.592) for the initial model indicates a moderate-strong linear relationship between the seven learner variables and Chinese Language Learning Anxiety. 
The seven variables combined to explain $35.1 \%$ of the variance in Chinese Language Learning Anxiety, which indicates a large effect size according to Cohen's (1988) criteria for determining the effect of a set of independent variables. The Adjusted R Square indicating the estimated coefficient for the population was $33.2 \%$.

Table 3. Initial multiple regression model for predicting CFL anxiety

\begin{tabular}{lcccc}
\hline \multirow{2}{*}{ Variable } & Standardized Coefficients & & Sig. & $\begin{array}{c}\text { Squared partial correlation } \\
\text { coefficients (\%) }\end{array}$ \\
\cline { 2 - 2 } (Intercept) & Beta & & & \\
Motivation & -.175 & -2.519 & .012 & 2.50 \\
Age & .154 & 2.968 & .003 & 3.46 \\
Language Learning Ability & -.197 & -3.367 & .001 & 4.37 \\
Self-expectation & .080 & 1.132 & .259 & 0.52 \\
Importance of Chinese & -.020 & -.282 & .778 & 0.03 \\
Self-perceived Achievement & -.250 & -4.404 & .000 & 7.29 \\
Difficulty of Chinese & .279 & 5.227 & .000 & 9.99 \\
\hline
\end{tabular}

Model R = .592; R Square = .351; Adjusted R Square $=.332 ;$ Std. Error $=9.49 ; F(7,254)=19.06, p=.0001$

Moreover, five variables (i.e., motivation, age, self-perceived language learning ability, self-perceived achievement, and perception of the difficulty of the Chinese language) had significant contribution to the prediction of Chinese language learning anxiety at the 0.01 level, whereas two variables (i.e., perception of the importance of Chinese and selfexpectation in learning Chinese) were not significant predictors ( $p=.259, .778)$.

The squared partial correlation coefficients were often recommended to assess the relative contribution of individual variables in multiple regression analysis (e.g., Cohen, 1988). According to the squared partial correlation coefficients, perception of the difficulty of the Chinese language was the best predictor of Chinese Language Learning Anxiety, explaining $9.99 \%$ of the variance on its own. The unique contribution of self-perceived achievement was the second largest, accounting for $7.29 \%$ of the variance, followed by selfperceived language learning ability and age, with motivation explaining the least amount of variance among all the significant predictors, explaining $4.37 \%, 3.46 \%$, and $2.50 \%$ of the variance in anxiety respectively.

Interestingly, the two variables, perception of the importance of Chinese and selfexpectation in learning Chinese, reported to correlate significantly with anxiety in the correlation analysis, were found not to be significant predictors in the multiple regression analysis when all the seven variables were examined simultaneously. In order to seek explanations for this result, Table 4 presents the correlation matrix of the seven variables. 
Table 4. Correlation matrix of the seven independent variables

\begin{tabular}{lccccccc}
\hline & $\mathbf{1}$ & $\mathbf{2}$ & $\mathbf{3}$ & $\mathbf{4}$ & $\mathbf{5}$ & $\mathbf{6}$ & 7 \\
\hline 1 Self-expectation in learning Chinese & 1 & $.57^{* *}$ & $.38^{* *}$ & $.53^{* *}$ & $-.15^{* *}$ & -.02 & $.43^{* *}$ \\
2 Perception of Importance of Chinese & $.57^{* *}$ & 1 & $.19^{* *}$ & $.62^{* *}$ & $-.14^{*}$ & .05 & $.29^{* *}$ \\
3 Self-perceived achievement & $.38^{* *}$ & $.19^{* *}$ & 1 & $.25^{* *}$ & $-.20^{* *}$ & -.10 & $.26^{* *}$ \\
4 Motivation & $.53^{* *}$ & $.62^{* *}$ & $.25^{* *}$ & 1 & $-.16^{* *}$ & .03 & $.36^{* *}$ \\
5 Perceived difficulty level of Chinese & $-.15^{* *}$ & $-.14^{*}$ & $-.20^{* *}$ & $-.16^{* *}$ & 1 & .09 & $-.20^{* *}$ \\
6 Age & -.02 & .05 & -.10 & .03 & .09 & 1 & .01 \\
7 Self-perceived language learning ability & $.43^{* *}$ & $.29^{* *}$ & $.26^{* *}$ & $.36^{* *}$ & $-.20^{* *}$ & .01 & 1 \\
\hline
\end{tabular}

**. Correlation is significant at the 0.01 level.

*. Correlation is significant at the 0.05 level.

As the matrix shows, self-expectation in learning Chinese had a moderate significant correlation with the perception of the importance of Chinese $(r=.57, p<.01)$. In addition, self-expectation in learning Chinese was also found to significantly correlate with motivation $(r=.53)$, self-perceived language learning ability $(r=.43)$, and self-perceived achievement $(r=.38)$ at the 0.01 level. Similarly, perception of the importance of Chinese was reported to have a significant moderate correlation with motivation $(r=.62)$ and significant slight correlations with self-perceived language learning ability $(r=.29)$ and self-perceived achievement $(r=.19)$ at the 0.01 level. Although these correlations are not high individually, moderate correlations among independent variables may still confound the effect of predictors in multiple regression (Stevens, 2009). This may partly explain the above mentioned result related to perception of the importance of Chinese and selfexpectation in learning Chinese.

Since perception of the importance of Chinese and self-expectation in learning Chinese were found not to be significant predictors of Chinese Language Learning Anxiety, they were removed from the list of independent variables in the final model. The results of Multiple Regression analysis of this model were reported in Table 5. After the two variables were removed, there was only a slight drop for R Square (.351 vs. .347), indicating that perception of the importance of Chinese and self-expectation in learning Chinese only accounted for $0.4 \%$ of the variance in Chinese Language Learning Anxiety. The five variables in the final model explained $34.7 \%$ of the variance in Chinese Language Learning Anxiety. 
Table 5. Final multiple regression model for predicting CFL anxiety

\begin{tabular}{|c|c|c|c|c|}
\hline \multirow{2}{*}{ Variable } & Standardized Coefficients & \multirow{2}{*}{$\mathrm{t}$} & \multirow{2}{*}{ Sig. } & \multirow{2}{*}{$\begin{array}{l}\text { Squared partial correlation } \\
\text { coefficients (\%) }\end{array}$} \\
\hline & Beta & & & \\
\hline (Intercept) & & 8.635 & .000 & \\
\hline Motivation & -.155 & -2.745 & .006 & 2.92 \\
\hline Age & .152 & 2.941 & .004 & 3.25 \\
\hline Language Learning Ability & -.180 & -3.191 & .002 & 3.92 \\
\hline Self-perceived Achievement & -.233 & -4.260 & .000 & 6.81 \\
\hline Difficulty of Chinese & .280 & 5.265 & .000 & 9.99 \\
\hline
\end{tabular}

Model $\mathrm{R}=.589 ; \mathrm{R}$ Square $=.347$; Adjusted R Square $=.334$; Std. Error $=9.47 ; F(5,254)=26.49, p=.0001$

Adjusted R Square for this model was slightly larger than for the initial model (.334 vs. .332), and the standard error decreased (9.49 vs. 9.47), indicating "a better match between the predicted and the observed values of participants' anxiety scores" (Tóth, 2007, pp. 136137).

In this model, the two best predictors of Chinese Language Learning Anxiety remained perception of the difficulty of the Chinese language and self-perceived achievement, followed by self-perceived language learning ability, age, and motivation.

The final multiple regression model shows that students with the highest level of anxiety tended to have one of the following characteristics: perceiving the Chinese language to be difficult, expecting to get a high grade in Chinese class, perceiving themselves to be poor at foreign language learning, being older, or having low motivation in learning Chinese.

\section{Discussion}

The present study investigated the relationship between anxiety among L2 learners of Chinese and the seven selected learner variables and provided interesting results. Perception of the difficulty of the Chinese language was found to be the largest correlate in isolation and the best predictor in the presence of other variables, lending support to the assumption that the foreignness or characteristics of the target language may have an impact on learners' Foreign Language Anxiety (Aida, 1994; Luo, 2012; Saito, Garza, \& Horwitz, 1999). The significant, positive relationship between anxiety and perception of difficulty of the Chinese language reported in this study was consistent with earlier findings in the literature (e.g., Saito, Garza \& Horwitz, 1999; Zhao \& Whitchurch, 2011). Saito, Garza, and Horwitz (1999) found students' levels of reading anxiety increased with their perceived difficulty of reading in French, Japanese, and Russian. Zhao and Whitchurch (2011) reported that Chinese language students who perceived the Chinese course as harder than they expected had higher levels of anxiety than those who thought otherwise.

Self-perceived achievement was reported to be the second largest correlate of anxiety 
in isolation and the second-best predictor when examined together with other learner variables. This finding is consistent with those of earlier studies as MacIntyre, Noels, and Clément (1997) and Onwuegbuzie, Bailey, and Daley (1999) also identified self-perceived achievement to be one of the top significant predictors of Foreign Language Anxiety. The moderate, negative correlation between self-perceived achievement and anxiety level reported in this study also provides indirect support for the moderate, negative relationship between Foreign Language Anxiety and actual language achievement consistently reported in previous studies (Horwitz, 2001). Although the grades students expect to get in Chinese class may not be an exact representation of their actual achievement, it should be highly correlated with their real performance in the class. However, it is hard to tell whether anxiety causes low achievement or low achievement causes anxiety as both directions are possible. While high levels of anxiety experienced by students are likely to affect their language performance, poor learning outcomes in language classes, real or perceived, may lead to the feeling of anxiety especially for students who attach great importance to grades in class.

A weak, negative relationship was reported between motivation and anxiety in this study, which corroborates some earlier studies (e.g., Clément, Dörnyei, \& Noels, 1994; Gardner, Day, \& MacIntyre, 1992; Gardner, Lalonde, \& Pierson, 1983), but contradicts Tóth's (2007) finding that the correlation between motivation and anxiety did not reach a significantly level among Hungarian first-year English majors. The negative relationship found between motivation and anxiety may be interpreted in four different ways (cf. Onwuegbuzie, Bailey, \& Daley, 1999): 1) high levels of anxiety demotivate students in Chinese learning; 2) low motivation in Chinese learning elevates their levels of anxiety; 3) motivation and anxiety affect each other reciprocally as suggested by some researchers (e.g., Gardner \& MacIntyre, 1993b); and 4) one or more other variables that are associated with both anxiety and motivation moderate the relationship between the two constructs. Moreover, learners and teachers in Luo's (2011) interview study posed the possibility that extremely motivated students could be highly anxious. Such cases have also been identified in other studies (e.g., Horwitz, 1996; Jackson, 2002; Kitano, 2001), which may indicate a potential positive relationship between motivation and Foreign Language Anxiety. Therefore, there is possibility that the relationship between the two constructs is non-linear.

Self-perceived language learning ability was also found to be a significant predictor both in correlation analysis and the final multiple regression model. The negative relationship found between self-perceived foreign language learning ability and Chinese language learning anxiety provided support for the findings of previous studies (Ganschow et al., 1994; Horwitz, 1990, 1995; Luo, 2011). This is likely because learners who perceive themselves to have better language learning ability tend to be more confident in foreign language learning. However, the small effect of this variable reported in this study did not seem to support Ganschow and Sparks' view that language learning ability was the most important cause of Foreign Language Anxiety.

The negative relationship found between age and Chinese language learning anxiety echoed the findings of some earlier research (Crook, 1979; Hunt, 1989; Onwuegbuzie, 
Bailey, \& Daley, 1999). Research has reported that older people tend to focus more on accuracy than younger people (Salthouse \& Somberg, 1982). Because Chinese is a tonal and character-based language, the delicate differentiation among tones and strokes of characters may pose a great challenge for older learners, to whom accuracy matters greatly. It is also possible that older learners tend to worry more about negative feedback from others, which has been suggested as causing anxiety in the literature (Luo, 2012).

Perception of the importance of Chinese and self-expectation in learning Chinese were found to be significant predictors of anxiety only in isolation, not in the presence of the other learner variables. Such seemingly inconsistent results may be explained by the considerable overlap between the two variables and the other independent variables in the multiple regression model. Further examination of correlation analyses among the seven learner variables indicated that self-expectation in learning Chinese was significantly correlated with motivation $(r=.476, p=.001)$, self-perceived foreign language learning ability $(r=.393, p=.001)$, and self-perceived achievement $(r=345, p=.001)$. Similarly, perception of the importance of Chinese had a moderate-strong and significant correlation with motivation $(r=.555, p=.001)$ and self-expectation $(r=.547, p=.001)$. These significant correlations among the dependent variables may explain why the unique contributions of perception of the importance of Chinese and self-expectation in learning Chinese to the prediction of anxiety were very small when the other five variables were present in the model.

A close examination of the five significant predictors of anxiety in the final model shows that three of them are related to learners' self-perceptions: self-perceived achievement, self-perceived foreign language learning ability, and perception of the difficulty of the Chinese language. This result was consistent with the findings of previous studies. Tóth (2007) found that L2-self-concept, a composite of L2-related selfperceptions, explained the greatest proportion of the variance in foreign language anxiety. Onwuegbuzie, Bailey, and Daley (1999) reported that three indicators of self-perceptions (i.e., expected final foreign language course average, perceived self-worth, and perceived scholastic competence) were the best predictors of foreign language anxiety among 26 correlates. These findings supported assumptions of earlier studies that learners' beliefs about themselves as foreign language learners play a key role in their experiences of foreign language anxiety (e.g., Horwitz, 1990; Price, 1991).

The five learner variables in the final regression model accounted for $34.7 \%$ of the total variance in Chinese Language Learning Anxiety, which is a considerable amount bearing in mind the large number of other potential factors associated with foreign language anxiety. However, $65.3 \%$ of the variance remained unexplained. Therefore, future research into other factors associated with Chinese language learning anxiety could be conducted to explore the issue. 


\section{Conclusions, Limitations, and Implications}

The present study examined seven correlates of Chinese language learning anxiety. The finding that students' perception of the difficulty of Chinese was the best predictor of anxiety may indicate that L2 learners of Chinese in the sample were possibly intimidated by the foreignness (i.e., tones and characters) of the Chinese language. Chinese instructors may need to conduct orientation workshops to demystify the Chinese language, informing the students that Chinese, though tonal and non-alphabetic, has many characteristics that make it easy to learn. For example, Chinese grammar is very easy as its verbs do not conjugate, unlike languages such as French and German. Chinese instructors could also show examples of successful English-speaking learners of Chinese, convincing them that it is completely possible for foreign language speaking learners to learn Chinese well. It may also be useful if Chinese instructors could give students opportunities to discuss their frustrations or difficulties in learning Chinese openly so that students know they are not alone in the struggle. Furthermore, instructors may need to explicitly teach some learning strategies specifically for tones and characters to alleviate their fear towards these two foreign characteristics of Chinese.

Consistent with the findings of some earlier studies (Onwuegbuzie, Bailey, \& Daley, 1999; Tóth, 2007), this study found students' self-perceptions such as self-perceived achievement and self-perceived foreign language learning ability were significant predictors of Chinese Language Learning Anxiety. Since students' beliefs about themselves in terms of foreign language learning may cause anxiety, it is important for instructors to know the students well. Therefore, language instructors should be encouraged to hold individual meetings with the students to discuss their beliefs and perceptions and direct them to the right track when erroneous beliefs or biased negative self-perceptions are discovered. In addition, it may also be useful for language instructors to have knowledge of students' perception of difficulty level of the four language skills and the learning activities and learning contexts that are anxiety-provoking so that they can adjust their teaching accordingly.

This study also found that age had a significant negative impact on Chinese language learning anxiety both in isolation and in the company of other learner variables. Since studies have suggested that younger learners tend to be better at learning finer points of a language such as phonology (Lieberman, 1984; Newport, 1986), educators may need to encourage students to take foreign languages, especially a relatively difficulty language like Chinese, at an earlier age, for example, in high school or even in elementary school. This suggestion was echoed by Onwuegbuzie, Bailey, and Daley (1999), who found students who had not taken any high school foreign language had higher levels of anxiety than their more language-experienced counterparts among college-level students.

In this study, anxiety was found to be positively correlated with perception of the difficulty of the Chinese language, but negatively correlated with motivation and selfperceived achievement. These findings may provide some insight for Chinese language teaching. Since more exposure to the Chinese language might reduce the difficulty level of Chinese perceived by the students, teachers may need to introduce more resources for 
learning Chinese and create more opportunities for the students to be exposed to Chinese after class. For example, the teachers can create a virtual Chinese community online or involve the students in all kinds of activities organized by local Chinese communities. These real-life involvements are often related to Chinese culture, which may enhance students' interest and motivation in learning Chinese. More exposure may lead to perception of less difficulty; more involvements may lead to higher motivation; higher motivation may lead to more efforts; more efforts may lead to better performance; better performance may lead to more positive self-perceptions. All these, hopefully, could lead to lower levels of anxiety over learning Chinese as a foreign language.

Finally, this study is a quantitative pursuit without incorporating qualitative analyses. Detailed qualitative explorations of the topic through interviews or observations on issues such as the sources of Chinese language learning anxiety or the relationships between anxiety and language skills, learning activities and learning contexts would be desirable and meaningful.

\section{References}

Aida, Y. (1994). Examination of Horwitz, Horwitz, and Cope's construct of foreign language anxiety: The case of students of Japanese. Modern Language Journal, 78, 155-168.

Cheng, Y. S. (2002). Factors associated with foreign language writing anxiety. Foreign Language Annals, 35, 647-656.

Clément, R. (1980). Ethnicity, contact and communicative competence in a second language. In H. Giles, W. P. Robinson, \& P. M. Smith (Eds.), Language: Social psychological perspectives (pp. 147-154). Oxford: Pergamon.

Clément, R. (1986). Second language proficiency and acculturation: An investigation of the effects of language status and individual characteristics. Journal of Language and Social Psychology, 5, 271-290.

Clément, R., Dörnyei, Z., \& Noels, K. A. (1994). Motivation, self-confidence, and group cohesion in the foreign language classroom. Language Learning, 44, 417-448.

Cohen, J. (1988). Statistical power analysis for the behavioral sciences. Hillsdale, NJ: Erlbaum.

Cohen, Y., \& Norst, M. J. (1989). Fear, dependence and loss of self-esteem: Affective barriers in second language learning among adults. RELC Journal, 20, 61-77.

Coulombe, D. (2000). Anxiety and beliefs of French-as-a-second-language learners at the university level. Unpublished doctoral dissertation, University of Laval, Quebec, Canada.

Crook, T. H. (1979). Psychometric assessment in the elderly. In A. Raskin \& L. F. Jarvik (Eds.), Psychiatric symptoms and cognitive loss (pp. 207-220). New York: Halstead.

Eysenck, M. W. (1979). Anxiety, learning and memory: A reconceptualization. Journal of Research in Personality, 13, 363-385.

Ganschow, L., \& Sparks, R. (1991). A screening instrument for the identification of foreign language learning problems. Foreign Language Annals, 24, 383-398.

Ganschow, L., \& Sparks, R. L. (1996). Anxiety about foreign language learning among high school women. Modern Language Journal, 80, 199-212. 
Ganschow, L., Sparks, R., Anderson, R., Javorsky, J., Skinner, S., \& Patton, J. (1994). Differences in language performance among high-, average-, and low-anxious college foreign language learners. Modern Language Journal, 78, 41-55.

Gardner, R. C. (1985). Social psychology and second language learning: The role of attitudes and motivation. London: Edward Arnold.

Gardner, R. C., Day, J. B., \& MacIntyre, P. D. (1992). Integrative motivation, induced anxiety, and language learning in a controlled environment. Studies in Second Language Acquisition, 14, 197-214.

Gardner, R. C., Lalonde, N., \& Pierson, R. (1983). The socio-educational model of second language acquisition: An investigation using LISREL causal modelling. Journal of Language and Social Psychology, 2, 1-15.

Gardner, R. C., \& MacIntyre, P. D. (1993a). On the measurement of affective variables in second language learning. Language Learning, 43, 157-194.

Gardner, R. C., \& MacIntyre, P. D. (1993b). A student's contributions to second language learning. Part II: Affective variables. Language Teaching, 26, 1-11.

Horwitz, E. K. (1986). Preliminary evidence for the reliability and validity of a foreign language anxiety scale. TESOL Quarterly, 20, 559-562.

Horwitz, E. K. (1988). The beliefs about language learning of beginning university foreign language students. Modern Language Journal, 72, 283-294.

Horwitz, E. K. (1990). Attending to the affective domain in the foreign language classroom. In S. S. Magnan (Ed.), Shifting the instructional focus to the learner (pp. 15-33). Middlebury, VT: Northeast Conference on the Teaching of Foreign Languages.

Horwitz, E. K. (1995). Student affective reactions and the teaching and learning of foreign languages. International Journal of Educational Research, 23, 573-579.

Horwitz, E. K. (1996). Even teachers get the blues: Recognizing and alleviating non-native teachers' feelings of foreign language anxiety. Foreign Language Annals, 29, 365-372.

Horwitz, E. K. (2001). Language anxiety and achievement. Annual Review of Applied Linguistics, 21, 112-126.

Horwitz, E. K., Horwitz, M. B., \& Cope, J. (1986). Foreign language classroom anxiety. Modern Language Journal, 70, 125-132.

Horwitz, E. K., Tallon, M., \& Luo, H. (2010). Foreign language anxiety. In J. Cassady (Ed.) Anxiety in schools: The causes, consequences, and solutions for academic anxieties (pp. 95-115). New York: Peter Lang.

Horwitz, E. K., \& Young, D. J. (1991). Language anxiety: From theory and research to classroom implications. Upper Saddle River, NJ: Prentice Hall.

Hunt, E. (1989). Introduction: Historical perspective and current considerations. In T. Hunt \& C. J. Lindley (Eds.), Testing older adults (pp. 1-17). Austin, TX: Pro-Ed.

Jackson, J. (2002). Reticence in second language case discussions: Anxiety and aspirations. System, $30,65-84$.

Kitano, K. (2001). Anxiety in the college Japanese language classroom. Modern Language Journal, $85,549-566$.

Le, J. (2004). Affective characteristics of American students studying Chinese in China: A study of heritage and non-heritage learners' beliefs and foreign language anxiety. Unpublished doctoral 
dissertation, University of Texas at Austin, Austin, TX.

Lieberman, P. (1984). The biology and evolution of language. Cambridge, MA: Harvard University Press.

Liu, M. (2006). Anxiety in Chinese EFL students at different proficiency levels. System, 34, 301-316.

Liu, M., \& Huang, W. (2011). An exploration of foreign language anxiety and English learning motivation. Educational Research International. Retrieved at http://www.hindawi.com/ journals/edu/2011/493167/.

Luo, H. (2011). Construction of a Chinese as a foreign language (CFL) anxiety scale: Towards a theoretical model of foreign language anxiety. Unpublished doctoral dissertation, University of Texas at Austin, Austin, TX.

Luo, H. (2012). Sources of foreign language anxiety: Towards a four-dimension model. Contemporary Foreign Language Studies, 12, 49-61.

Luo, H. (2013a). Chinese language learning anxiety and its associated factors. Journal of Chinese Language Teachers Association, 48, 109-133.

Luo, H. (2013b). Foreign language anxiety: Past and future. Chinese Journal of Applied Linguistics, $36,442-464$.

Luo, H. (2014a). A measure of Chinese language learning anxiety: Scale development and preliminary validation. Chinese as a Second Language Research, 3, 147-174.

Luo, H. (2014b). Foreign language speaking anxiety: A study of Chinese language learners. Journal of the National Council of Less Commonly Taught Languages, 15, 99-117.

Luo, H. (2015). Chinese language learning anxiety: A study of heritage learners. Heritage Language Journal, 12, 22-47.

MacIntyre, P. D. (1999). Language anxiety: A review of the research for language teachers. In D. J. Young (Ed.), Affect in foreign language and second language learning: A practical guide to creating a low-anxiety classroom atmosphere (pp. 24-45). Boston, MA: McGraw-Hill College.

MacIntyre, P. D., \& Charos, C. (1996). Personality, attitudes, and affect as predictors of second language communication. Journal of Language and Social Psychology, 15, 3-26.

MacIntyre, P. D., \& Gardner, R. C. (1989). Anxiety and second-language learning: Toward a theoretical clarification. Language Learning, 39, 251-275.

MacIntyre, P. D., \& Gardner, R. C. (1991a). Methods and results in the study of anxiety in language learning: A review of the literature. Language Learning, 41, 85-117.

MacIntyre, P. D., \& Gardner, R. C. (1991b). Investigating language class anxiety using the focused essay technique. Modern Language Journal, 75, 296-304.

MacIntyre, P. D., \& Gardner, R. C. (1994). The subtle effects of language anxiety on cognitive processing in the second language. Language Learning, 44, 283-305.

MacIntyre, P. D., Noels, K. A., \& Clément, R. (1997). Biases in self-ratings of second language proficiency: The role of language anxiety. Language Learning, 47, 265-287.

Newport, E. L. (1986). The effect of maturational state on the acquisition of language. Paper presented at the Eleventh Annual Boston University Conference on Language Development, Boston, MA.

Onwuegbuzie, A. J., Bailey, P., \& Daley, C. E. (1999). Factors associated with foreign language anxiety. Applied Psycholinguistics, 20, 217-239.

Phillips, E. M. (1992). The effects of language anxiety on student oral test performance and 
attitudes. Modern Language Journal, 76, 14-26.

Price, M. L. (1991). The subjective experience of foreign language anxiety: Interviews with highly anxious students. In E. K. Horwitz \& D. J. Young (Eds.), Language anxiety: From theory and research to classroom implications (pp. 101-108). Upper Saddle River, NJ: Prentice Hall.

Saito, Y., Garza, T. J., \& Horwitz, E. K. (1999). Foreign language reading anxiety. Modern Language Journal, 83, 202-218.

Salthouse, T. A., \& Somberg, B. L. (1982). Isolating the age deficit in speeded performance. Journal of Gerontology, 37, 59-63.

Sarason, I. G. (1980). Test anxiety: Theory, research and applications. Hillsdale, NJ: Erlbaum.

Shi, R. J. (2007). Liuxuesheng hanyu yuedu jiaolü yingfu fangshi yanjiu [The study on coping with language anxiety in learning Mandarin by foreign students]. Xiandai yuwen, 2, 99-101.

Sparks, R. L., \& Ganschow, L. (1995). A strong inference approach to causal factors in foreign language learning: A response to MacIntyre. Modern Language Journal, 79, 235-244.

Spitalli, E. J. (2000). The relationship between foreign language anxiety and attitudes toward multicultarilism in high-school students. Unpublished master's thesis, Benedictine University, Lisle, IL.

Stevens, J. (2009). Applied multivariate statistics for the social sciences. New York/London: Routledge.

Tobias, S. (1979). Anxiety research in educational psychology. Journal of Educational Psychology, 71, 573-582.

Tobias, S. (1986). Anxiety and cognitive processing of instruction. In R. Schwarzer (Ed.), Self-related cognition in anxiety and motivation (pp.35-54). Hillsdale, NJ: Erlbaum.

Tóth, Zs. (2007). Predictors of foreign language anxiety: Examining the relationship between anxiety and other individual learner variables. In J. Horvath \& M. Nikolov (Eds.), UPRT 2007: Empirical studies in English applied linguistics (pp. 123-148). Pecs: Lingua Franca.

Xiao, Y., \& Wong, K. F. (2014), Exploring heritage language anxiety: A study of Chinese heritage language learners. Modern Language Journal, 98, 589-611.

Zhang, L. (2001). Liuxuesheng hanyu xuexi jiaolügan yu kouyu liulixing guanxi chutan [Relation between foreign students' learning anxiety and their fluency of spoken Chinese]. Yuyan wenzi yingyong, 39, 44-49.

Zhang, L. (2002). Liuxuesheng hanyu yuedu jiaolügan yanjiu [Anxiety of Overseas Students in Chinese Reading]. Yuyan wenzi yingyong, 44, 77-83.

Zhang, L., \& Wang, B. (2002). Liuxuesheng hanyu jiaolügan yu chengji xiangguan fenxi ji jiaoxue duice [Analysis of the relationship between foreign students' anxiety about Chinese language and achievement and teaching strategies]. Yuyan jiaoxue yu yanjiu, 164, 36-42.

Zhao, A. (2009). Foreign language reading anxiety: Investigating English-speaking university students learning Chinese as a foreign language in the United States. Unpublished Doctoral Dissertation, Florida State University, Tallahassee, FL.

Zhao, A., Guo, Y., \& Dynia, J. (2013). Foreign language reading anxiety: Chinese as a foreign language in the United States. Modern Language Journal, 97, 764-778.

Zhao, A., \& Whitchurch, A. (2011). Anxiety and its associated factors in college-level Chinese classrooms in the U.S. Journal of Chinese Language Teachers Association, 46, 21-47. 


\section{About the author}

Dr. Han LuO is currently a Visiting Assistant Professor of Chinese at Lafayette College in the United States. She received a PhD in Foreign Language Education with a specialization in the teaching of Chinese from the University of Texas at Austin in 2011, and a PhD in Linguistics and Applied Linguistics from Beijing Foreign Studies University in 2007. Her research interests include second language acquisition, teaching Chinese as a foreign language, foreign language learning anxiety, cognitive linguistics, heritage language education, and online intercultural exchange. Email: luohan78@gmail.com 